\title{
The Awesome Ordinary: Notes on Pro Wrestling
}

\author{
Guillermo Rebollo Gil \\ UNIVERSIDAD DEL ESTE (CAROLINA, PUERTO RICO)
}

This article offers a critical, idiosyncratic take on the staging of sincerity in pro wrestling. It engages this popular cultural product as an athletic performance event, with the intention of highlighting the affective underpinnings of fans' interest in and connection with the medium. Specifically, it is argued here that the lack of legitimate competition in wrestling allows for images, meanings and feelings of cooperation and complicity to come to the forefront. The article serves, also, as an off-beat reflection on essay and poetry writing.

\section{KEYWORDS}

pro wrestling, sincerity, the ordinary, everyday life, poetry 


\section{Pro Wrestling: The Basics}

At the heart of pro wrestling sits this basic fact: it is sincere. Performers play the role of legitimate opponents, who willingly put their bodies in peril in choreographed, yet largely improvised, bouts. Bouts feature damaging and daring maneuvers that, in order to be executed properly, require subtle and timely assists from those who sustain the brunt of the blow. Sincerity here is understood as performers' engagement in assisting their slated opponents in telling a compelling story by way of their "execution" in the ring. Execution here is understood as the measure of a performers' ability to dramatize the extent of the damage sustained (and/or given) while efficiently (and convincingly) delivering the bout to its pre-determined result. Combatants must work in tandem to give the impression of true animosity and utter disregard for each other's well-being. The success of a wrestling match thus depends on the care, coordination, and cooperation between opponents (Smith 2014). In this very precise sense, pro wrestling is an affair of the heart.

This essay's opening sentence is adapted from CNN's Chris Cillizza's column "Why Pro Wrestling is the Perfect Metaphor for Donald Trump's Presidency"; the original reads: "At the heart of pro wrestling sits this basic fact: It is fake" (Cillizza 2017). Cillizza, a self-identified wrestling fan, wants to make a point: not about wrestling, but about Trump's presidency. Particularly, about the President's feigned disdain for mainstream media, when a large chunk of his success (entrepreneurial, political or otherwise) can be attributed to his deep-seated obsession with the media industry. Unfortunately, according to Cillizza, some proportion of America's general public fall prey to Trump's fakery, as they-like many wrestling fans-are much too prone to believe anything they see, read or hear. And so, wrestling as a metaphor is "perfect" insomuch as President Trump, like wrestling promoters, relies on staged conflicts to captivate audiences. The problem, of course, as Cillizza puts it, is that: "[w]restling is fake. Being President isn't. Trump seems not to know or care about this distinction” (Cillizza 2017).

This essay does not care about Donald Trump. It cares about wrestling. Specifically, it cares about the careless manner in which some critics and commentators, like Cillizza, point to wrestling's fakery to identify a problem, both in the medium itself and as a metaphor for social and political processes outside of it. As with other modes of performance, that wrestling is staged is the least intriguing 
of its basic facts. Moreover, as R. Tyson Smith (2014) argues, "the fakery fixation distracts from other important meanings" (2). In particular, the fixation with fakery as a problem of professional wrestling distracts from fakery's own important meanings as they may become apparent during a match. While, yes, wrestlers fake-hit their opponents, who in turn fake the harm caused by their aggressors, the fakery of the hit and/or the harm isn't what, ultimately, distinguishes wrestling as a performance form. Insomuch as mostly everything that happens in the ring is staged at one level or another, what stands out is the, at times coordinated, at times improvised, but, always cooperative motion of wrestlers' bodies. What stands out is the work being done by performers to make each and every fake hit and fake harm flow into another for purposes of the performance. Thus, wrestlers don't so much fake in-ring action as they-through great effort-embody fakery, set it in motion as part of a live-action event. One important meaning that fakery acquires in pro wrestling, then, is how necessary it might be for the sustainment of human life. At least as it pertains to scenarios when bodies come into quick, violent contact with one another. Fakery is what makes it possible for bodies to grab, press, and slam into one another without causing real harm.

There is, I think, sincerity in this. In the manner in which bodies are only made to look as if they're harming one another inside the ring, all the while each and every move performed is intended to keep the bodies safe (Smith 2014). The action in the ring is sincere insomuch as the poses, holds, and maneuvers that make caring possible during a match and which make wrestling matches possible over time, are never truly hidden from view. The intention then is not to deceive audiences. Nor does the medium, in order to be enjoyed, truly require fans to willingly suspend their disbelief and let themselves be taken by the storylines. It is both more complex and more illuminating than that: it is about the interplay between what seems to be going on in the match and what is actually happening between performers. In-ring conflict compels audiences only in so far as wrestlers manage to work together; to help and care for one another. Audiences, in turn, applaud at the end because their favorite performer won a thrilling clash. Or they applaud out of appreciation for the thrills of the dance-or both.

This is, I think, what is always there to be seen in wrestling. The confluence of the fake and the sincere as embodied by those who step inside the ring, and as 
experienced by those watching. Unfortunately, critics often get distracted when they turn their attention to wrestling and end up treating it as a metaphor for, or a symptom of, something purportedly more serious. Like the state of American culture or of the American Presidency. On the occasions in which wrestling is broached with no ulterior motives, critical appraisals are frequently plagued by moralistic concerns regarding the almost always crude, and often downright offensive, storylines and their potentially harmful effects on the viewing public. In either case, wrestling remains at the threshold of critical consideration: we look to it in an effort to look past it, toward something of greater social and/or political consequence.

It takes a fan to look at something like pro wrestling and make a "critical and joyful fuss" (Haraway 2016, 3) solely about the action in the ring, and be content with that. That is why Cillizza's article is so disheartening. He treats wrestling as a proxy for politics. In doing so, wrestling is reduced to the one thing that those unfamiliar with, or uninterested in, the medium can claim to "know" about it without ever having watched a match: that it's staged. Such a reductive analysis amounts to an act of dispossession. To reduce wrestling to its fakery as a problem not only distracts from its other (more important) meanings as outlined above, but it obscures performers' bodies from view ridding them of their agency, and disregarding the effect that their bodies in motion may have over fans. At the heart of this essay sits this basic fact: I am a wrestling fan. This is my sincere attempt at writing like one.

\section{The Impossible Question: Wrestling and Writing}

In his treatise on the essayistic form, Brian Dillon (2017) considers the possibility of writing an essay "simply out of the things at hand at the moment" (123). As such, the essay becomes an exercise in both constraint and indulgence: I turn to write with whatever I have on me, and what I have on me I have because it is my favorite. I have sat down to write this essay with a poetry book by W. Todd Kaneko open face down across my lap. I've also hit play on a recording of the most recent episode of WWE's weekly Smackdown Live wrestling program. On my desk there is a CM Punk action figure. If I manage to close this essay with elegance, I'll treat myself to raising the doll's arms in victory. 
Kaneko's poetry book is entitled The Dead Wrestler Elegies. It's mostly the same poem over and over again, chronicling his relationship with his dad, a huge wrestling fan; his dad's relationship with his mother, she left; and pro wrestlers' relationship with pain and fame and life in general, they all die in the end. My favorite lines of verse in the book reads as follows:

the impossible question-

have you ever won?

(1. 23-24)

The question is posed posthumously to famed female wrestler Judy Grable. After my initial reading, I searched for but could not find Grable's win-loss record online. There is something bizarre about responding to a poem by searching for the facts. It is an impossible response, for nothing I potentially uncover could ever debunk (or confirm) a single line of poetry. Yet, the exercise was necessary insomuch as it allowed me to get a better handle on Kaneko's wrestling themed verses and, through them, on wrestling itself.

Pro wrestling isn't about winning or losing. Regardless of how successful a record, or how lengthy a title reign, no performer has ever really won a pro wrestling match. Smith (2014) explains: "From the standpoint of the performers, the objective is not winning per se but winning the crowd over with a great story" (102). Critics thus position wrestling as a sui generis athletic performance event that draws from both sport and theatre, but escapes the basic principles, confines, and conventions that define and legitimate each (Chow et al 2017). Wrestling is unlike sport in that there is no actual competition, and it is unlike theatre in that there is an ever present, and often purposely exacerbated, uncertainty regarding what is scripted, what is improvised, what might be real, and what is accidental amongst everything that goes on in and out of the ring. The loose structure of bouts, which allows for performers' on the spot coordination and decision making, sets the stage for the unexpected: the deliberate strike from a disgruntled opponent; the inadvertent harm from a miscalculated blow or fall; the unexpected and ill-advised fan intrusion into the ring; the inclusion of real life controversies in performers' scripted verbal jabs against each other or in their commentary to the crowd; the collusion between promoter and performer to "screw" the latter's counterpart. The ring, as a performance space, is open to a much wider array of happenstance than traditional theatre. This is further heightened by wrestlers' 
historical penchant and, also, contractual obligation to (more or less) remain in character when in the public eye. Former wrestler and sociologist Laurence de Garis (1999) explains:

Professional wrestlers are trained to be convincing and often stay "in character" when people whom they do not know are around. [. . . In fact, veteran pro wrestlers themselves find difficulty in interpreting exactly what goes on when others are in the ring. The problem arises when attempting to summarize, conclude, or otherwise "nail down" events or behaviors (69).

Poet Russell Jaffe (2016) echoes de Garis, locating wrestling's appeal in "the subtleties, ... The way a wrestler runs his thumb through the top of his tights-tired, in control, taking a breather, adjusting to continue" (n.p.). de Garis and Jaffe focus on performers' bodies and their effect on onlookers. How wrestlers work in the ring, following de Garis, is often cryptic. One watches bodies enter into motion with each other, without necessarily being able to discern the motives and understandings that drive such motion. It is the motion that keeps us watching. Even the least spectacular gestures, such as the wrestler who suddenly stops for a breather in the middle of the match, can be captivating. People stop for breathers all the times, but it is not often that we stop to notice it. Then, of course, the wrestler will get hit from behind with a "death-defying" maneuver and end up losing the match in the most devastating fashion, only to, miraculously, show up the following week, ready for a new challenge. Each move in wrestling leads to another move, and each battle-to-end-all-battles leads to another match scheduled down the road. As Nicholas Sammond (2005) explains: "[w]restlers never learn from their mistakes, never see the error of their ways in retrospective regret, nor conquer the external forces that oppress them. Instead, the cycle repeats, over and over; the same mistakes, the same betrayals, the same evanescent victories and defeats" (6). In this very precise sense, wrestling matches are impossible to watch insofar as each is, more or less, a repetition of the previous one. Yet, if you're a fan, you watch because wrestling makes you feel something. This something, I think, is the ordinary.

\section{Pro Wrestling: This is Ordinary}

The cyclical nature of pro wrestling enacts the ongoing character of daily life perhaps better than any other performance form. After all, most people, like wrestlers, never learn from their mistakes, never see the error of their ways in retrospective regret, nor conquer the external forces that oppress them. Instead, 
the cycle repeats, over and over: the same mistakes, the same betrayals, the same evanescent victories and defeats. This is the story that performers tell with their bodies in the hope of winning the audience over.

For all its fakery, wrestling is what ordinary life looks like when stripped down to, well, Lycra bottoms, some face paint maybe, and a pair of boots. While critics love to highlight the out-of-world physiques and larger-than-life conflicts that pro wrestling is most notorious for, what the medium specializes in is making the struggle of everyday life, appear (almost entirely) in the nude. Wayne Koestenbaum (2013) writes: "[p]ut nude in the adjectival slot, and the noun automatically gets upgraded" (201). I think wrestling gives fans a glimpse into the nude-everyday. So much of the everyday is about subtleties, that it becomes difficult, if not impossible, for one to summarize, conclude, or otherwise "nail down" events or behaviors. Wrestling offers its fans a staging of the subtleties that constitute the ordinary. Fans, in turn, make a joyful (and often critical) fuss about it because, in the ring, the ordinary looks, and makes you feel, truly awesome.

Kathleen Stewart, in Ordinary Affects (2007), writes of this feeling as that which "catches people up in something that feels like something" (2). Something like the succession of moves in a match. She writes: "[o]rdinary affects are the varied, surging capacities to affect and be affected that give everyday life the quality of a continual motion of relations, scenes, contingencies, and emergences" (1-2). Stewart, here, proposes an engagement with the ordinary that requires us to be attentive to our heightened, though perhaps un-, or under-acknowledged, vulnerability to be won over (or beaten down) by whatever may be going on in our life; even if, or rather, especially if there is nothing really going on in our life. Other than the fact that it continues, of course. Outside the ring, the simplicity of the ongoingness of life may very well cause weariness. But, inside the ring, the very same thing will, if you're a fan, catch you up in a sensation.

For Barthes (1957), the sensation that pro wrestling offers audiences is "the transient images of certain passions" (1). For me, as a fan, what each individual match draws our attention to is the considerable amount of passion involved in just going through the motions day after day; of our willingness to be affected by life as it continues. I'm not saying that this is the most awesome part of life, but it is the part of life that is most present in and most vital to, a wrestling match. In this sense, neither the images nor the feelings they provoke are transient, for they make up overwhelming majority of the what goes on inside and outside the ring. In the ring, they get an upgrade; outside, they often become grating. 


\section{Pro Wrestling: This is Awesome}

The most awesome part of a wrestling match is this: opponents' cooperation and complicity always trumps the conflict between them. The truth is that no matter how well timed, it is impossible to hide one opponent's assistance in the other's attack. There is, I think, sincerity in that. In the expression, for example, of the wrestler who patiently waits on the outside of the ring, feigning injury, for his opponent to run, push off against the ropes on the far side and come flying out of the ring to land on top of him. If the sequence is executed properly, the wrestler on the receiving end of the blow always appears as if he were catching his opponent to break his fall; because he is. Then, once back in the ring, the one who leapt to the outside, or the one who broke his fall-it doesn't really matter who-will lie still with the other on top of him until the referee counts to three. One of them will celebrate and the crowd will jeer or cheer. But, again, there is no winning as such. There is only making as if one or the other won. There is only making with, in order to win the crowd over.

Critics often miss this part or pick up on it only to poke fun at the medium's fakery. But this is the part of the wrestling match fans and non-fans alike should most look out for: the making with. Which in my reading is very much like a "making do"; or, more precisely, a "making due." Each move executed in the ring is premised on a shared expectation, that it will be willingly received and assisted to ensure that the performing body lands safely. Wrestlers, on the surface, exchange strikes. But, on a more profound level, they trade opportunities for one another to be there for the other. It is how wrestling continues to be possible and why many of us, outside of the ring, sincerely wish and root for its continued practice. Moreover, this is the one part of the show that is very much a fixture, and that can most easily be performed outside of the confines of the ring, and yet, it often goes unnoticed or unremarked.

As a result, the type of questions wrestling makes possible are rarely ever posed, for example: have you ever wondered how one body can be forced, pressed under the weight of another; how it might be painful to be twisted by another's hands; how it can be willed into the brink of submission, until, suddenly, with the inexplicable help of the offending body, it rises? It is, in truth, an improbable scenario. And yet, each and every wrestling match offers audiences the opportunity to witness how the body of your slated opponent can turn towards you, in your favor. And insomuch as this turning is repeated time and again, in-ring 
action does not demand to be viewed, enjoyed and interpreted as the staging of an actual conflict, but rather as a live-action model of what collaboration might look like in the most unlikely of circumstances. In this vein, Ashley Souther (2007), in her article on a community based pro-wrestling program, argues that:

the very mechanism that allows an audience to believe that a man can be beaten so as to be unable to move while his opponent climbs the ring ropes to deliver a diving elbow-yet minutes later musters the inner strength to mount a stirring comeback (suspension of disbelief) — could also be used to believe what, in the current social context, would seem equally impossible: reconciliation of enemies, respect between rivals, and a new broader sense of community (273).

While for Souther, this mechanism is audiences' willing suspension of disbelief, I would venture to say that the mechanism she is referring to is fakery. Not as a problem, but as a contextual, embodied practice, by which the wellbeing of others is safeguarded-no matter the odds. This, at least, is one of the principal effects that wrestling has on me. It clarifies, in a manner that no other cultural-commercial production can, how starting with or from, our own body, we continually come up against and must turn to other bodies in order to continue day after day. There is, I think, sincerity in that. In the recognition that the seemingly impossible moves that wrestlers perform find correspondence in our mundane twists and turns. It's just that everyday life, contrary to wrestling, is not premised on a principle of willing collaboration amongst those we encounter. Thus, we often presume them to be our opponents and prefer to avoid them.

Often, in the everyday, when one for example, tries to make a life "simply out of the things at hand at the moment" (Dillon 2017, 123), it feels like there is no one there to turn to; to make something with; to break one's fall. The ordinary, one could argue, often feels lacking in feelings of complicity and cooperation. It is as if a subtle, but ever-present, conflict trumps everything else. And so, if you're a fan like me, and if you happen to have your favorite wrestling program playing on TV while you write, there is something that comes over you when you turn your attention from one screen to the other and see one performer catch another, both landing hard, but safely, on the outside of the ring. To borrow a sentiment from W. Koestenbaum's work, "Responding, I squint, sigh, snort, clench my molars. I jot a note on my private pad, or I comment aloud. I point. Elucidating, I play tour guide. I proclaim [wrestling's] triumph over depressing circumstances."1 Simply put, I make a fuss. This fuss is as joyous as it is critical. And most of all, it is sincere. I likely will not be able to close out this essay with elegance, but I'm going to raise my CM Punk doll's arms in victory anyway. 


\section{Endnotes}

1. The original reads: "I proclaim art's triumph over depressing circumstances" Kostenbaum, W. (2013). Why Art is Always Emotional. My 1980s \& Other Essays. New York: Farrar, Straus \& Girraux, 238.

\section{References}

Barthes, R. (1957). The World of Wrestling. [online], 1-4. Available at: https:// faculty.georgetown.edu/irvinem/theory/Barthes-Mythologies-Wrestling-1957.pdf [Accessed 5 Oct 2017].

Cillizza, C. (2017). Why Pro Wrestling is the Perfect Metaphor for Donald Trump's Presidency. CNN. Available at: http://edition.cnn.com/2017/07/02/ politics/trump-wrestling-tweet/index.html [Accessed 1 Sept 2017].

Chow, B. et al. (2017). Hamlet Doesn't Blade: Professional Wrestling, Theatre, and Performance. In B. Chow et al, ed. Performance and Professional Wrestling. London: Routledge, 1-6.

Dillon, B. (2017). Essayism. London: Fitzcarraldo Editions.

de Garis, L. (1999). Experiments in Pro Wrestling: Toward a Performative and Sensuous Sport Ethnography. Sociology of Sport Journal, 16, 1, 65-74. [online] Available at: http://fitnessforlife.org/AcuCustom/Sitename/Documents/DocumentItem/1696.pdf [Accessed 1 Sept 2017].

Haraway, D. (2016). Staying with the Trouble: Making Kin in the Chthulucene. Durham: Duke University Press.

Jaffe, R. (2016). I Wish More Poets Loved Pro Wrestling, or the Apocalyptic Postmodern Fanscape (with Examples). Entropy Magazine. Available at: https://entropymag.org/i-wish-more-poets-loved-pro-wrestling-or-theapocalyptic-postmodern-fanscape-with-examples/ [Accessed 1 Sept 2017].

Kaneko, W. (2014). The Dead Wrestler Elegies. Chicago: Curbside Splendor Publishing. 
Kostenbaum, W. (2013). Warhol's Interviews. My 1980s \& Other Essays. New York: Farrar, Straus \& Girraux, 236-239.

Kostenbaum, W. (2013). Why Art is Always Emotional. My 1980s \& Other Essays. New York: Farrar, Straus \& Girraux, 201-205.

Sammond, N. (2005). Introduction: A Brief and Unnecessary Defense of Professional Wrestling. In N. Sammond, ed. Steel Chair to the Head: The Pleasure and Pain of Professional Wrestling. Durham: Duke University Press, 1-20.

Smith, R. (2014). Fighting for Recognition: Identity, Masculinity and the Act of Violence in Professional Wrestling. Durham: Duke University Press..

Souther, A. (2007). Professional Wrestling as Conflict Transformation. Peace Review: A Journal of Social Justice, 19 (2), 269- 275.

Stewart, K. (2007). Ordinary Affects. Durham: Duke University Press. 